\title{
17 MIL MAGISTRADOS, 1 MILHÃO DE ADVOGADOS, 27 MILHÕES DE PROCESSOS NOVOS: NÚMEROS E PERSPECTIVAS DO SISTEMA JUDICIÁRIO BRASILEIRO
}

\author{
Wagner Silveira Feloniuk
}

\section{RESUMO}

Esta é uma pesquisa sobre o sistema judiciário brasileiro com apresentação de dados e reflexões sobre desequilíbrios. Há duas partes, na primeira são consolidados dados sobre o número de advogados, juízes e processos. Eles são estudados a partir da sua consolidação em metodologia única, baseada na população brasileira e na quantidade de processos. O Brasil é então comparado com Austrália, Canadá, França, Japão, Reino Unidos e Estados Unidos. Na segunda parte, dois elementos servem de contraponto, a mora processual e dados sobre as defensorias públicas. Com esses subsídios, reflete-se sobre os problemas existentes.

Palavras-Chave: Organização judiciária. Sistema judiciário brasileiro. Comparação entre judiciários. Número de advogados, processos e juízes.

\section{THOUSAND JUDGES, 1 MILLION LAWYERS, 27 MILLION NEW LAWSUITS: NUMBERS AND PERSPECTIVES ON THE BRAZILIAN JUDICIARY SYSTEM}

\begin{abstract}
This is a research on the Brazilian judicial system with data presentation and reflections on imbalances. There are two parts, in the first data on the number of lawyers, judges and lawsuits is consolidated. They are studied based on a consolidation in a single methodology, based on the Brazilian population and the number of lawsuits. Brazil is then compared to Australia, Canada, France, Japan, the United Kingdom and the United States. In the second part, two elements serve as a counterpoint, procedural delay and data on public defenders. With these information, there is a reflection on the existing problems.
\end{abstract}

Keywords: Judiciary organization. Brazilian judicial system. Comparation between judiciaries. Number of lawyers, lawsuits and judges.

\section{INTRODUÇÃO}

\footnotetext{
* Doutorado em Direito (2013-2016, bolsa CAPES), Mestrado Acadêmico (2012, bolsa CNPq), Especialização em Direito do Estado (2011) e Graduação em Ciências Jurídicas e Sociais com láurea acadêmica (2006-2010) na Universidade Federal do Rio Grande do Sul - UFRGS. Professor substituto de Direito do Instituto Federal do Rio Grande do Sul e das pós-graduações da Verbo Jurídico e Instituto de Desenvolvimento Cultural. EditorExecutivo da Revista da Faculdade de Direito da UFRGS (B1) e da Revista do Instituto Histórico e Geográfico do Rio Grande do Sul (B2), membro do Conselho Editorial da Revista E-Civitas (B4), da Revista Brasileira de Direitos Humanos da Lex Magister (B2), das editoras científicas DM e RJR. Ex-servidor da Corregedoria-Geral da Justiça do TJ/RS (2009-2016). Autor dos livros "A Constituição de Cádiz: Análise da Constituição Política da Monarquia Espanhola de 1812" e "A Constituição de Cádiz: Influência no Brasil". Pesquisador dos Grupos de Pesquisa CAPES: Supremacia do Direito e Direito e Filosofia. Membro da Associação Nacional de História, da Associação Brasileira de Editores Científicos, Conselho Nacional de Pesquisa e Pós-Graduação em Direito e Membro Pesquisador do Instituto Histórico e Geográfico do Rio Grande do Sul. Áreas de Pesquisa: Direito Constitucional, História do Direito, Teoria do Estado. Trabalho submetido em: 21 mai. 2017.
} 
Este trabalho une três grupos de elementos: primeiro, pesquisas de diversos órgãos estatais sobre as instituições judiciárias brasileiras; segundo, um estudo elaborado em Harvard com dados equivalentes aos dos órgãos brasileiros, mas de outros países; terceiro, pesquisas científicas e notícias de imprensa com dados sobre profissionais da área jurídica e dificuldades de acesso à Justiça.

Eles são unidos para montar um quadro compreensível dos números que compõe o sistema judiciário brasileiro. Fala-se em sistema, em um conjunto de elementos que compõe essa atividade social. Grande parte dela está organizada no ente que monopoliza o poder, o Estado, mas nem toda - há os advogados privados, a $\mathrm{OAB}$, cidadãos que são partes de processos - elementos que não fazem parte, em sentido estrito, da estrutura estatal. $O$ interesse é em dados principais que compõe o cenário, abrangendo também esses outros elementos sociais.

Diversas pesquisas são feitas no Brasil nessa área. Algumas delas, como as do Conselho Nacional de Justiça (CNJ), tem grande profundidade. A proposta no trabalho curto que segue é a de unir pesquisas que não são interpenetradas durante sua produção. O CNJ pesquisa prioritariamente o Judiciário, a OAB divulga dados sobre advogados, a Defensoria Pública sobre as necessidades de sua instituição. O esforço foi de colher dados centrais, apresentados com metodologias diferentes, e uni-los em estatísticas acessíveis e comparáveis a outros países, incentivando a reflexão sobre o cenário.

O trabalho tem duas partes. Uma é sobre o sistema judiciário em seus dados amplos. Com eles, toma-se conhecimento do número de processos, juízes, advogados, e se pode pensar em que áreas há desequilíbrios e como eles surgem. A segunda parte do trabalho é particularista, a mora processual e os números das defensorias públicas são escolhidas como parâmetros de reflexão sobre os dados gerais. O exercício da segunda parte tem a finalidade de ponderar sobre as dificuldades que as estatísticas mostram e também sobre realidades sentidas no quotidiano das profissões jurídicas que podem ser ocultadas se forem considerados apenas os dados amplos do sistema.

A segunda parte tem uma ligação com as dificuldades de acesso à Justiça. É possível estudar deficiências a partir de marcos como dificuldades econômicas, sociais, psicológicas, 
culturais, ou ainda com os avanços nas formas de acesso. Não são esses os objetivos aqui. A segunda parte trata de dados e estatísticas concretas voltadas às deficiências que o sistema tem e que podem ser modificadas com planejamento adequado.

\section{Números do Direito brasileiro e perspectiva comparada}

\subsection{Formação de bacharéis em Direito}

O Brasil tem $1.242^{1}$ cursos de Direito, em consulta feita em maio de 2017 ao sistema de cursos credenciados no Ministério da Educação (BRASIL, 2017)². Esse não é o número de faculdades, algumas instituições oferecem cursos em vários locais e cada um é listado separadamente, mas não parece exagero concluir que é um número elevado, mesmo com o dado inicial.

Se compararmos com dados de outros países, uma dimensão melhor pode ser percebida. Hélio Duque, traz dados da palestra do XXII Conferência Nacional dos Advogados. Foi informado que no resto do mundo somado, incluindo China, Estados Unidos, Europa, África, existiriam 1.100 cursos de direito e, ao menos naquele momento, o Brasil os superava com seus 1.240 (DUQUE, 2015, p. 1-2). Nos Estados Unidos há, em maio de 2017, 203 cursos reconhecidos (AMERICAN BAR, 2017) e outros países têm números semelhantes, na ordem das dezenas ou de até duas centenas ${ }^{3}$.

O resultado dessa ampla oferta e do interesse nas carreiras jurídicas pode ser visto nos números divulgados em novembro de 2016 pelo Conselho Federal da OAB. Eram 1,07 milhões de advogados inscritos. Os estados com mais profissionais eram São Paulo (282 mil),

\footnotetext{
${ }^{1}$ Desses, em 2016, a Ordem dos Advogados do Brasil reconheceu a excelência de 142, e essa excelência é apenas ter nota superior a 7, considerando cursos que participem com ao menos 20 alunos nos últimos três exames unificados para ingresso na ordem (NOVAES, 2016, p. 1-2). Novamente, são listados os cursos com excelência, o número de instituições de ensino superior é ainda menor - por exemplo, a UFPB, UNIR, USJT, UEMS são listadas duas vezes, a UESPI recebe o selo em três cursos diferentes.

${ }^{2}$ Consulta feita em 19 de maio de 2017, pelo portal e-MEC, nas Instituições de Educação Superior e Cursos Cadastrados.

${ }^{3}$ Há dados disponíveis de diversos países, mas em geral há grande incongruência entre os números nas tabelas encontradas, e as consultas aos dados conhecidos do Brasil e Estados Unidos confirmam a pouca confiabilidade. Dentre as fontes mais acessíveis, a Wikipedia continha corretos sobre os Estados Unidos e possivelmente pode servir para se estimar outros países. Nela são listados, por exemplo, 23 cursos na China, 152 na Índia, 58 na França, 23 no Paquistão, 17 na África do Sul, 20 na Turquia, 6 na Suécia e 15 na Polônia. Ainda que os números variem anualmente e possam haver erros, tais dimensões indicam que a proporção de cursos no Brasil em relação à sua população é realmente muito alta e que os dados apresentados na palestra, de 1.100 cursos no mundo, não estariam longe do correto.
} 
Rio de Janeiro (138 mil), Minas Gerais (102 mil) e Rio Grande do Sul (75 mil). Em outros termos, há um advogado para cada 205 habitantes, eles são 0,5\% da população (CONJUR, 2016). O número de não aprovados no exame da ordem era ainda maior. Nas estimativas apresentadas durante a discussão do projeto de Lei Federal n ${ }^{\circ}$ 5.749/2013, estimavam-se quase 5 milhões de pessoas (LISBOA, 2014, p. 1).

Um estudo da Harvard Law School, de John Mark Ramseyer, professor da instituição, e Eric B. Rasmusen, professor da Indiana University, mostrou seguinte número de advogados per capita em outros países (o Brasil é incluído por este autor):

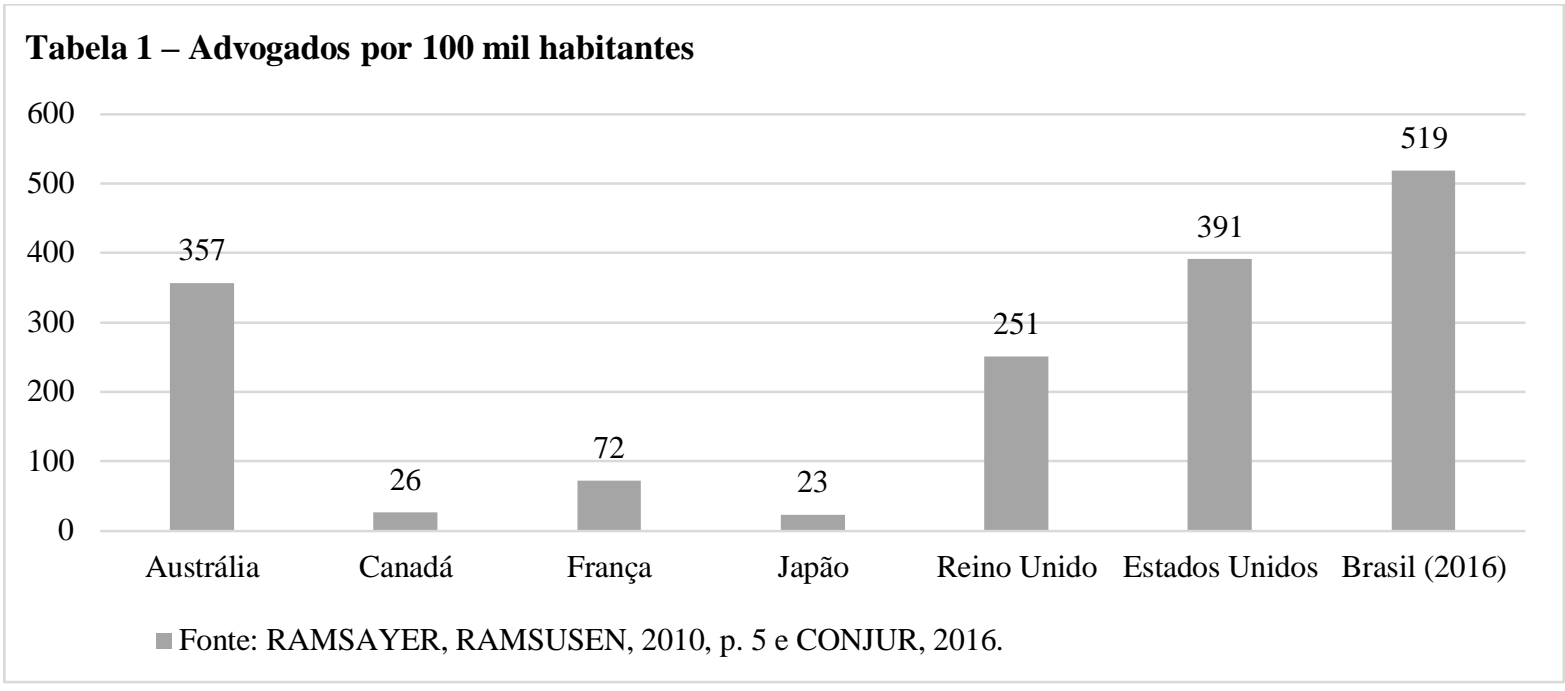

Na tabela, com dados de 2016, o Brasil tem 519 ativos na OAB para cada 100 mil habitantes.

Esses dados habitualmente trazem comentários sobre a proliferação de cursos, 0 tamanho do mercado de trabalho, a qualidade de ensino oferecida nas instituições. Menos de $20 \%$ dos bacharéis são advogados e isso é atribuído a diversos problemas dessa espécie. Mas os dados não permitem conclusões tão fáceis quanto pode parecer. Como exemplo simples dessa dificuldade, não há dados de quantos dos quatro milhões restantes fazem parte dos quase 25 milhões de servidores públicos brasileiros, e, na administração direta, que forma o maior grupo de servidores, 83,7\% tinha ensino de nível superior em 2012 (SARAIVA; MARTINS, 2013, p. 1-3). Haver um servidor público formado em Direito, ainda que sem estatística para se comprovar, não é um fenômeno raro. 
Apenas com os dados sobre advogados é difícil dimensionar o cenário brasileiro. Para continuar a análise é preciso ver o número de magistrados e processos per capita, isso é essencial para se compreender a dimensão desse número de advogados no Brasil.

\subsection{Magistrados e novos processos por ano}

Justiça em Números é o nome do relatório anual publicado desde 2004 pelo Conselho Nacional de Justiça, ele é instrumento de grande importância para compreender as virtudes e dificuldades do Judiciário brasileiro e será aqui utilizado para comparar o Brasil com outros países. O mais recente publicado é de 2016. Ali são feitos os estudos das 90 cortes e 15.773 unidades de primeiro grau existentes no Brasil (CONSELHO, 2016, p. 30-31).

Um dado inicial é quanto ao número de magistrados, são 17.338. Novamente utilizando os dados de Ramsayer e Ramsusen, apresentam-se os seguintes dados dos países:

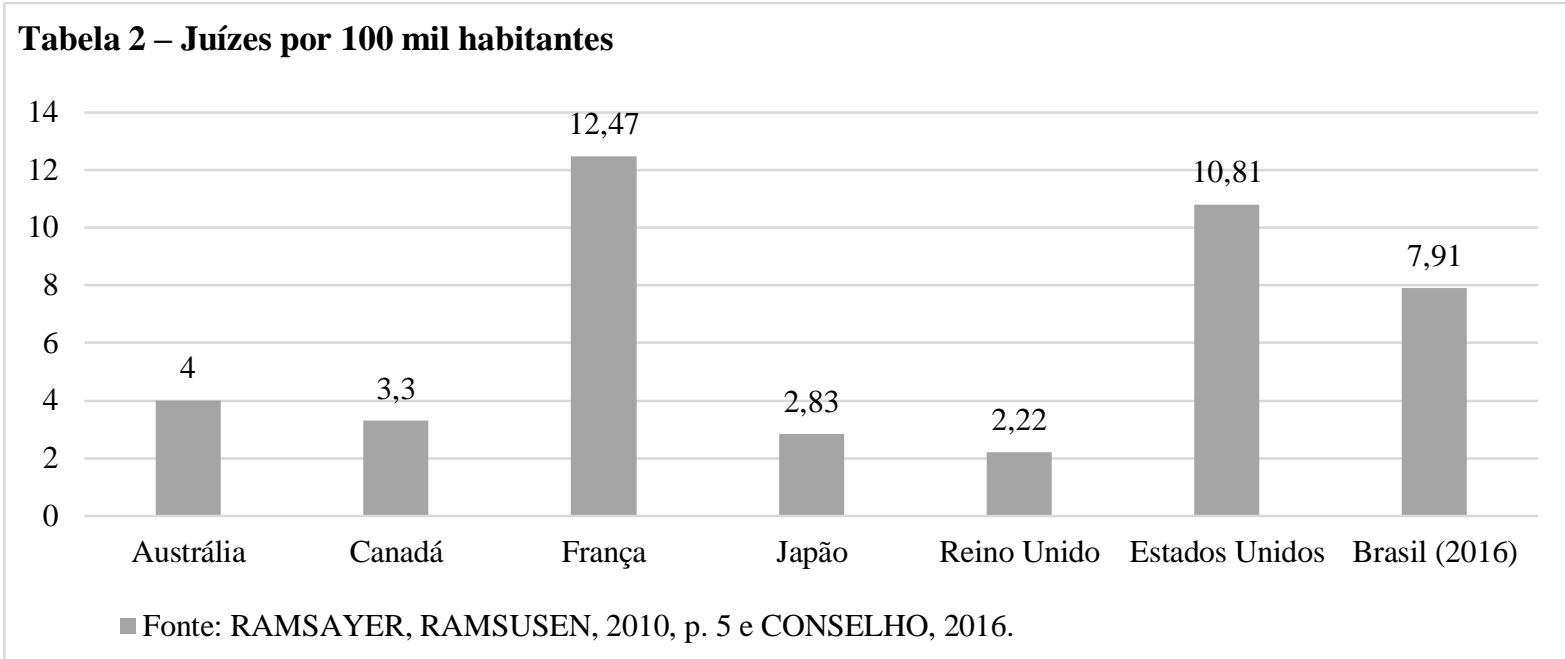

O Brasil, inserido com os dados atuais, tem 7,91 magistrados para cada 100 mil habitantes na tabela (CONSELHO, 2016, p. 38). Desses, 68,2\% são da Justiça Estadual, 20,6\% da Justiça do Trabalho, 10,3\% da Justiça Federal e o demais se dividem entre outros ramos e tribunais superiores. Os dados colocam-nos abaixo da França e dos Estados Unidos da América e a frente dos demais países. Apesar do grande número de magistrados no Brasil, não há diferença relevante quando comparado. O Brasil não parece longe da normalidade.

O número de processos, por outro lado, não traz a mesma perspectiva que o de magistrados. Ele afasta o Brasil da normalidade e se aproxima dos dados sobre o número de 
advogados. O Brasil teve 27,3 milhões de novos processos iniciados no ano-base 2015 e há, atualmente, 73,9 milhões de processos em tramitação, com um ingresso crescente de novos casos a cada ano. O Judiciário conseguiu aumentar o número de julgamentos, mas não em ritmo suficiente, como se pode notar no número de casos pendentes abaixo. Dos 27,3 milhões, 1.931.542 eram processos criminais iniciados no primeiro grau (CONSELHO, 2016, p. 62) - o número de processos criminais é destacado porque sua resolução rápida é um fator de grande relevância para a garantia de direitos no Brasil - esse trabalho retomará esse dado.

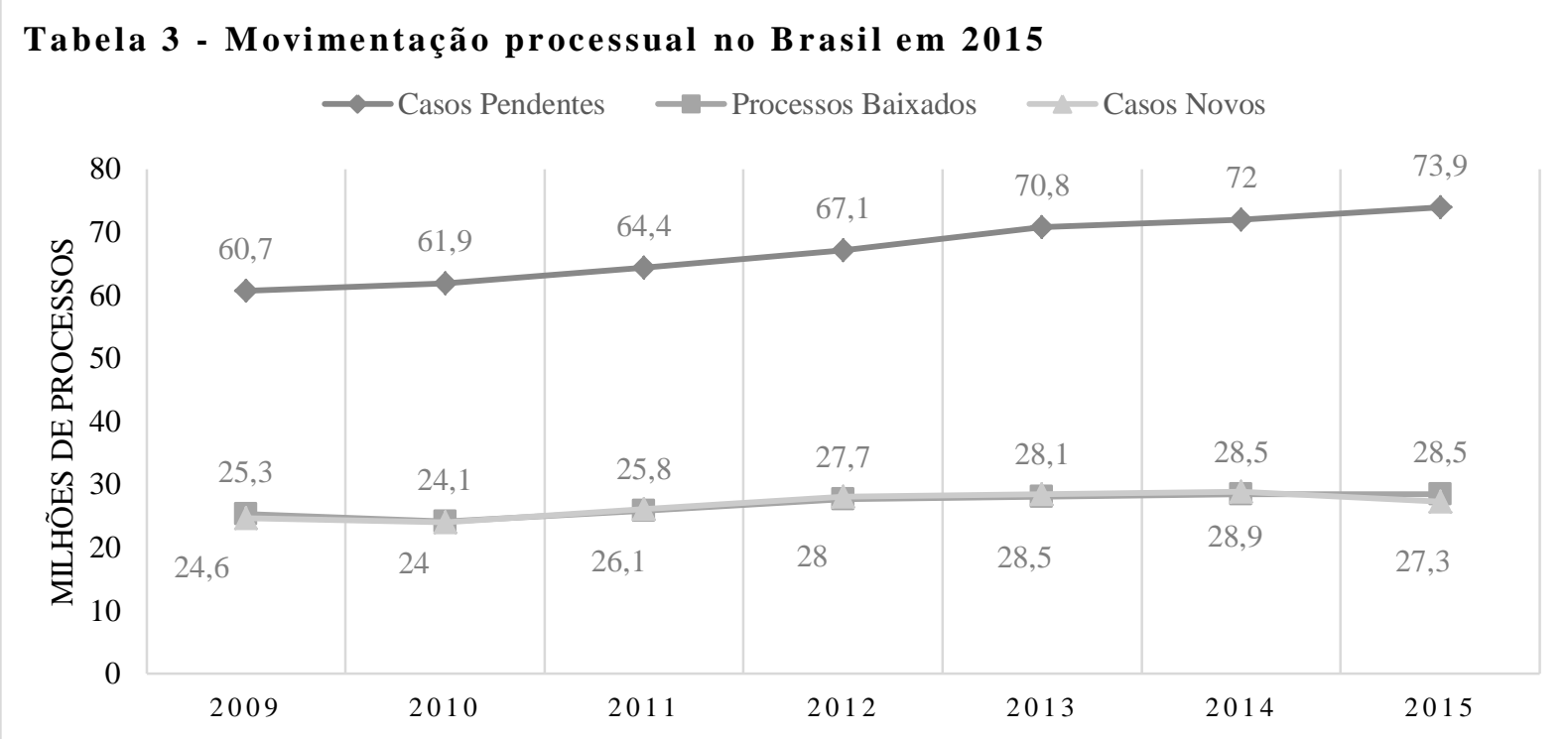

FONTE: CONSELHO, 2016, P. 43.

Em número de processos por cem mil habitantes, o trabalho dos professores norteamericanos traz os seguintes dados: 


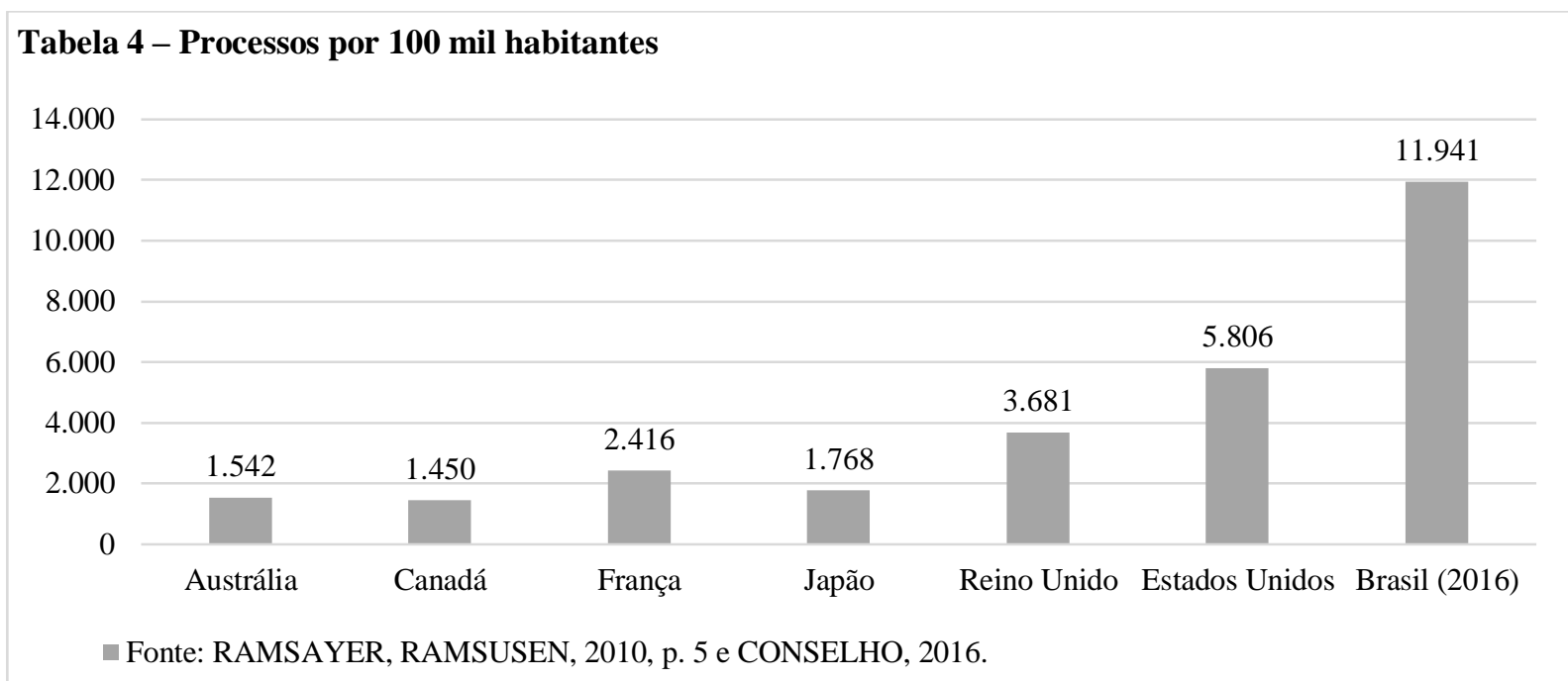

O Brasil, adicionado à tabela original, tem 11.941 casos novos por 100.000 habitantes (CONSELHO, 2016, p. 44). Ou seja, a taxa de litigância duas vezes superior à dos Estados Unidos, um país que tradicionalmente é visto como de alta taxa e maior do que qualquer outro país apresentado no estudo de Ramsayer e Ramsusen.

Compilando os dados até agora trazidos, podemos chegar a algumas conclusões parciais comparando Estados Unidos e Brasil, dois países com populações assemelhadas e taxas altas de processos por habitante. Os dados apontam resultados contra-intuitivos e que desafiam crenças consolidadas. Não é raro se pensar que há um grande número de magistrados no Brasil. No entanto, há proporcionalmente menos no Brasil do que nos Estados Unidos $(10,81$ contra 7,91 juízes por 100 mil habitantes), e os dos Estados Unidos precisam julgar menos da metade dos casos que os brasileiros (5,806 contra 11,941 casos por cem mil habitantes).

Mais importante ainda, nota-se que nessa proporção por 100 mil habitantes, os Estados Unidos têm proporcionalmente 75,33\% dos advogados do Brasil (391 norte-americanos contra 519 brasileiros) mas têm apenas 48,62\% dos processos do Brasil. Há, portanto, menos advogados, mas bem menos processos. Proporcionalmente, então, há mais carga para os advogados brasileiros.

\subsection{Casos por juiz e por advogado}

As duas próximas estatísticas vão mostrar mais claramente os efeitos dos dados. Considerando os dados da $\mathrm{OAB}$, do Justiça em Números e dos professores norte-americanos, 
é possível fazer estimativas sobre quantos processos cabem a cada juiz e a cada advogado por país.

No caso dos juízes, a divisão entre o total de casos por 100 mil habitantes e o total de magistrados gera os seguintes resultados:

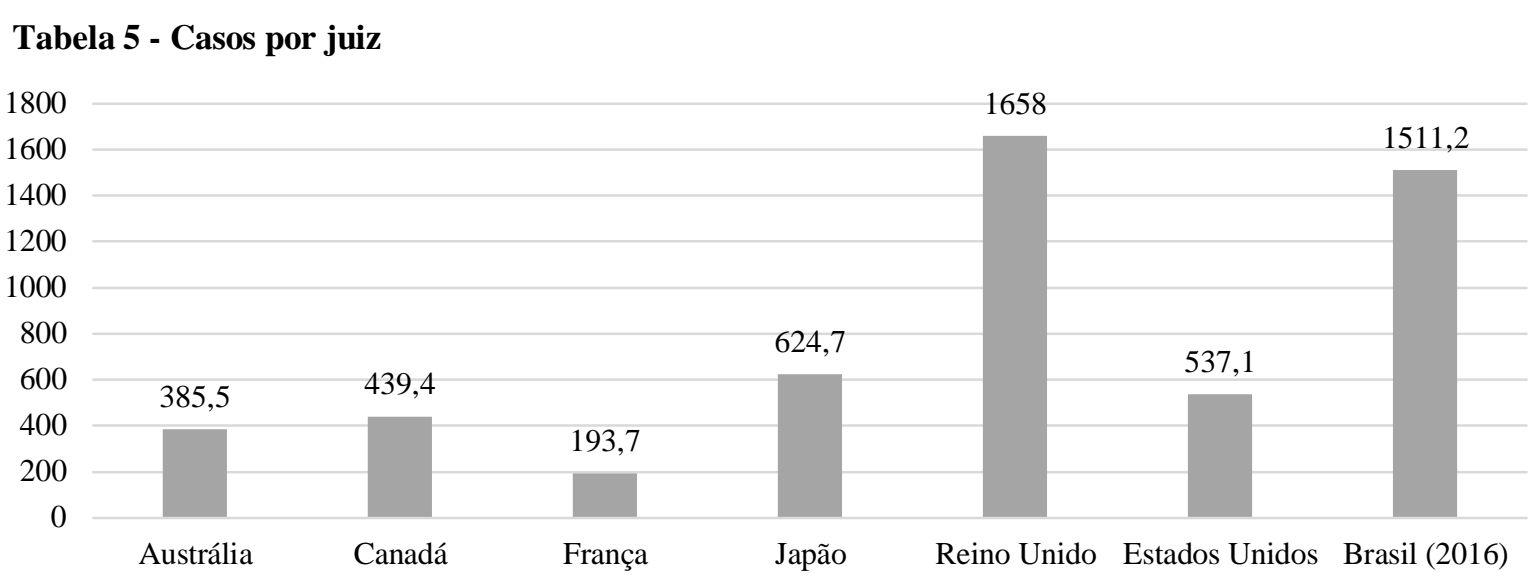

— Fonte: RAMSAYER, RAMSUSEN, 2010, p. 5, CONJUR, 2016, CONSELHO 2016.

Em análise, os juízes brasileiros são responsáveis por um grande número de casos, 1511 por magistrado. Dentre os países com dados disponíveis, apenas os juízes do Reino Unido têm uma carga maior.

No caso de advogados, os números são os seguintes:

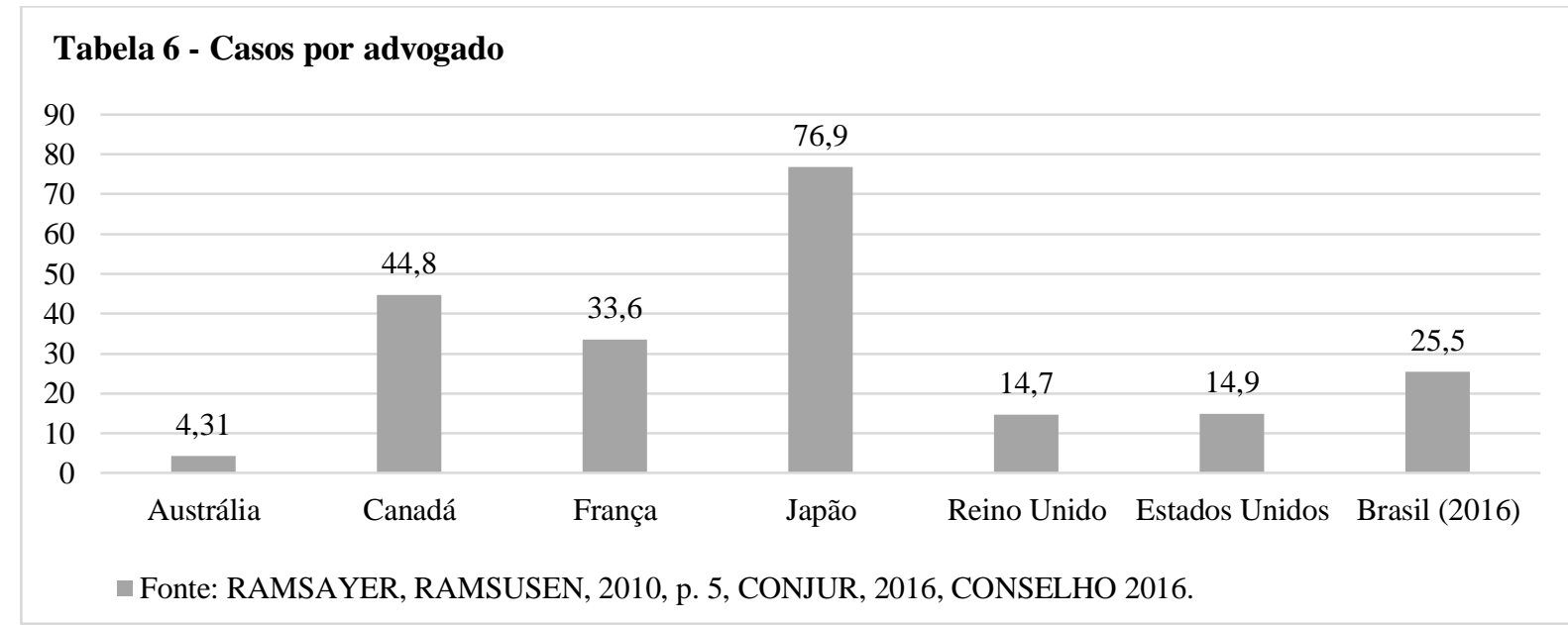


Os advogados brasileiros são responsáveis por um número intermediário de casos. São 1,07 milhões de advogados e cerca de 27,3 milhões de processos iniciados a cada ano, então há 25,5 casos por advogado. Esses dados sugerem que o número de advogados não estaria fora da normalidade em relação a outros países. Há, aproximadamente, metade dos advogados em relação ao Canadá e um terço em comparação ao Japão. O indício que essas estatísticas trazem é que o problema brasileiro possivelmente está mais ligado à deficiência no ensino jurídico e má distribuição de profissionais do que na consideração de quantos advogados mantém vínculo com a Ordem dos Advogados - algo que os dados sobre as defensorias públicas corroboram a frente.

Os dados trazem, em suma, um quadro de alta litigiosidade na população, ela é acompanhada pelo número de advogados, mas não pelo de magistrados. Os magistrados produzem muito no exercício jurisdicional pois, apesar do número de processos, há a resolução em um ritmo quase tão grande quanto de ingressos. O número de processos em tramitação não deixou de aumentar, o que demonstra a insuficiência do sistema, mas se está bastante próximo desse patamar. Os advogados, por sua vez, estão presentes em grande número, mais de um milhão, mas são tantos processos que os dados brutos indicariam, sem todas as nuances da realidade, que não há anormalidades manifestas.

Estatísticas, no entanto, não servem para esclarecer situações sociais complexas e esse é o caso nesses dados. No Brasil, paradoxalmente, estão presentes duas realidades antagônicas. Uma é que o número de advogados parece alto. Diversas vezes os profissionais não conseguem se inserir na carreira ou ter rendimentos dentro das expectativas (MOSSINI, 2010, p. 39) (FERNANDES-FERREIRA, 2016) e as críticas à qualidade dos cursos voltados apenas a formar grande quantidade de novos profissionais é constante (SILVA, 2008) (SILVA, 2012, p. 46) (MOSSINI, 2010, p. 39-42 e 179-186) (STRECK, 2016). Por esse lado, parece que há muitos advogados no mercado. A outra realidade é o número de presos provisórios, a deficiência na assistência gratuita e tantas outras dificuldades que parecem indicar que, de alguma forma, há locais em que os advogados não estão tão presentes quanto o necessário.

\section{Dois números sobre as deficiências no acesso à Justiça e prestação jurisdicional}

O segundo conjunto de números a serem apresentados trata das deficiências. Ao contrário do primeiro bloco, que tinha a função de abranger todo o sistema judiciário e a 
compará-lo com outros países, essa seção parte de "outro tipo de estatísticas". Essas são as estatísticas que mostram os problemas, elas são mais particularistas, de áreas específicas, de temas de reconhecida deficiência. Apesar de também serem números, elas são um contraponto à seção anterior - servirão para mostrar em que momento ter 25,5 processos por advogado informa pouco, pois esse um dado de um sistema repleto de complexidades. Com eles, buscase a outra peça necessária para entender o quadro e fazer propostas - o lado que mostra para onde devem ser focados os recursos existentes.

Ao afastar-se de estatísticas sobre o sistema considerado integralmente, surge a necessidade de escolha dos temas. A escolha deles é arbitrária, não há um guia, tampouco há a garantia de que as feitas são as mais relevantes. O critério foi escolher pontos que afetem um grande número de pessoas, causem um impacto financeiro relevante e deem origem a violações severas a direitos reconhecidos na Constituição. Em suma, estatísticas que ainda guardem alguma semelhança com os dados sistemáticos apresentados antes. Nesse sentido, foram escolhidos dados sobre as defensorias públicas e o tempo de duração dos processos no Brasil. Eles complementam os dados do sistema sem se afastar excessivamente deles, matizando a realidade mostrada.

\subsection{Defensorias públicas}

A Defensoria Pública é a estrutura institucional criada pelo Estado brasileiro para garantir o acesso daqueles que não tem como remunerar pelos serviços de um advogado privado. O Ministério Público tem atribuições que o aproximam dessa prestação em algumas áreas, há outras instituições públicas e privadas com serviços próximos, mas as defensorias foram planejadas como via principal de acesso quando há impedimento por carência financeira. Dada a desigualdade econômica que marca a sociedade brasileira, um grande número de pessoas dependem dessa estrutura para acessar o Poder Judiciário e por isso sua escolha na pesquisa.

Como introdução, é interessante o texto constitucional que as introduz, alterado recentemente pela $E C \mathrm{n}^{\circ}$ 80, de 2014, e instrutivo sobre o papel e dimensão da instituição:

Art. 134. A Defensoria Pública é instituição permanente, essencial à função jurisdicional do Estado, incumbindo-lhe, como expressão e instrumento do regime democrático, fundamentalmente, a orientação jurídica, a promoção dos direitos humanos e a defesa, em todos os graus, judicial e extrajudicial, dos direitos 
individuais e coletivos, de forma integral e gratuita, aos necessitados, na forma do inciso LXXIV do art. $5^{\circ}$ desta Constituição Federal (BRASIL, 1988).

Dois parágrafos sobre a história das defensorias introduzem o ponto a ser tratado a frente. As iniciativas para assistência jurídica gratuitas são antigas. Como narra Silva, elas aparecem mesmo nas Ordenações Filipinas, Livro III, Título 84. Mais tarde, durante a criação da Ordem dos Advogados Brasileiros, em 1870, Joaquim Nabuco criou estruturas, inclusive nas comissões seccionais, para que membros dessem consultas e defendessem em juízo as pessoas sem condições (SILVA, s.d., p. 1-3). A estruturação estatal só foi iniciada, no entanto, na Constituição de 1934, com o artigo 113, item 32, (BRASIL, 1934), que ordenava à União e aos Estados a criação de órgãos especiais para dar assistência e assegurar isenção de taxas. Poucos anos depois, o Código de Processo Civil, de 1939, trataria de regras para essa prestação, e elas foram organizadas, afinal, na Lei Federal n 1.060 de 1950 (BRASIL, 1950). Essa última lei continua em vigor, mas foi revogada em grande parte de suas normas pelo Código de Processo Civil de 2015.

A primeira estrutura institucional de prestação ocorreria pouco depois (SILVA, s.d., p. 1-3). Foi no estado do Rio de Janeiro, pela Lei Estadual $n^{\circ} 2.188$, de 1954, que seis cargos de Defensor Público foram criados dentro da estrutura da Procuradoria-Geral de Justiça, mas eram cargos isolados nas carreiras. Pouco depois, o Distrito Federal implementaria seu serviço de assistência, com a Lei Federal no 3.434, em 20 de julho de 1958 - nessa lei ainda ocorre a indiferenciação em relação ao Ministério Público:

\footnotetext{
Art. $3^{\circ}$ Aos órgãos do Ministério Público, em geral, incumbe promover ou fiscalizar a execução das leis, notadamente:

I - promover a ação penal e a execução das sentenças, nos casos e pela forma que prevêem as leis em vigor, assim como assegurar a defesa dos acusados que não tenham constituído defensor, ou quando êste não se achar presente; (BRASIL, 1958).
}

Essa narrativa histórica serve para mostrar o quão nova é essa estrutura no Brasil e como é recente a sua separação de outras atividades estatais como, por exemplo, a persecução penal. A estabilização de um serviço tão amplo é um movimento de décadas, exige estruturas físicas, concursos, criação de leis, alterações no sistema processual, e não surpreende que ainda não esteja plenamente concretizada. Apesar de outros avanços antes da Constituição atual, foi só em 1988 que o modelo de uma instituição permanente e com o objetivo de 
universalizar o acesso à Justiça no Brasil foi estabelecido e foi inserido em um plano de tratamento semelhante às outras instituições judiciárias.

Os dados mais recentes sobre a defensoria são de 2015, trazidos com a publicação do IV Dianóstico da Defensoria Pública no Brasil pelo Ministério da Justiça (GONÇALVES; BRITO; FILGUERA, 2015, p. 5). Apesar dos avanços, o processo de implantação ainda está em curso. Havia apenas seis defensorias antes de 1988, duas foram criadas de 1988 até 1990, nove criadas até o ano 2000, sete criadas até 2010 e a de Santa Catarina, a mais recente, é de 2012. O Amapá, até a publicação, não implantara a sua (GONÇALVES; BRITO; FILGUERA, 2015, p. 5 e 19).

Além do estado do Amapá, diversas comarcas brasileiras não têm defensores públicos, especialmente nas regiões Norte e Nordeste (GONÇALVES; BRITO; FILGUERA, 2015, p. 11). Dados do IPEA de 2013, no estudo "Mapa da Defensoria Pública no Brasil", apontam que $95,4 \%$ das comarcas brasileiras tem déficit e dois terços desse percentual não tem qualquer atendimento da defensoria. Apenas 12,7\%, 124 comarcas no Brasil, tem o percentual considerado adequado naquela metodologia, de necessidade de ao menos um defensor para cada 10 mil habitantes. As estatísticas do IPEA trazem que a maior necessidade de defensores no Brasil é nas áreas de Família e Sucessões e nas áreas de processos e execuções criminais. Os dados diagnosticam deficiências nessas áreas e, de maneira geral, em áreas como combate à violência contra a mulher, defesa de idosos e pessoas com deficiência, defesa do consumidor, infância e juventude (MOURA, 2013, p. 39-41).

Por todo o cenário, o total de defensores públicos ativos, ainda que seu número cresça rapidamente, mostra uma realidade muito afastada do sistema que considera o total de advogados. Há 6.062 defensores públicos no Brasil. Nos métodos utilizados, há 2,928 defensores por 100 mil habitantes.

Há uma ressalva, a Defensoria Pública tem como público-alvo os habitantes maiores de 10 anos e possuidores de renda familiar de até 3 salários mínimos. Nem todos os brasileiros são sujeitos preferenciais da prestação ${ }^{4}$. Ainda assim, de acordo com os números fornecidos

\footnotetext{
${ }^{4} \mathrm{O}$ atendimento não é feito apenas aos que se enquadram no perfil de vulnerabilidade econômica, além de situações onde a vulnerabilidade jurídica é reconhecida, há diversos outros campos em que se discute a possibilidade de atendimento e engloba um número alto de pessoas: "[a] doutrina de vanguarda, além disso, enuncia a existência da hipossuficiência organizacional para albergar todos aqueles que são socialmente vulneráveis: os consumidores, os usuários de serviços públicos, os usuários de planos de saúde, os que queiram implementar ou contestar políticas públicas, como as atinentes à saúde, à moradia, ao saneamento básico, ao meio ambiente etc. É no campo da hipossuficiência organizacional que a Defensoria Pública deflagra as ações coletivas" (NEGREIROS, RODRIGUES, 2015, p. 183).
} 
pelo relatório, 80,72 milhões de brasileiros estão nessa faixa de renda familiar e tem mais de dez anos (GONÇALVES; BRITO; FILGUERA, 2015, p. 44-45) - ou seja, quase metade da população brasileira faz parte do público-alvo, menores de dez anos não são contados, mas algumas famílias precisam da assistência também para eles. Ainda que amenizado por esse público-alvo menor, e mesmo se ele fosse o único a mobilizar a capacidade das defensorias, ainda são apenas 7,5 defensores para cada 100 mil habitantes. O contraste é grande:

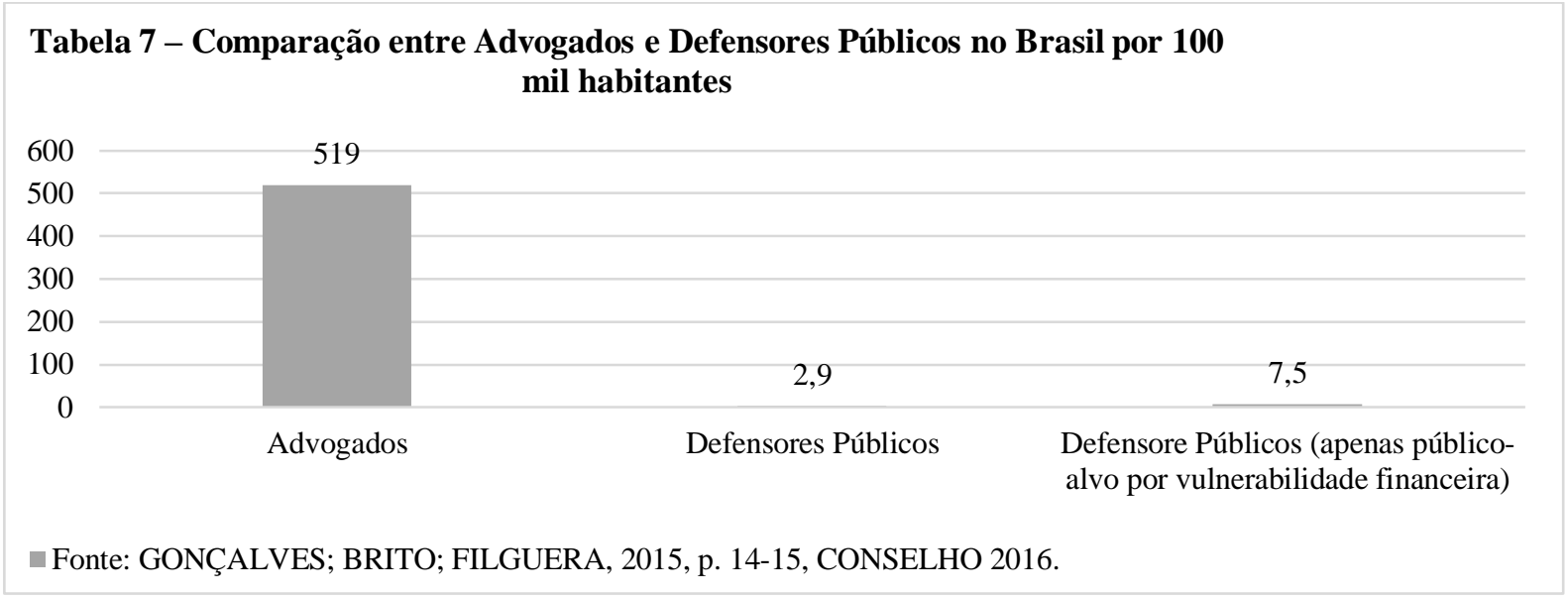

Por mais que as defensorias tenham servidores e estruturas que possibilitem o acompanhamento de um grande número de processos, os dados indicam que o acesso à Justiça por esse meio tem limitações sérias. Há prestação também de advogados dativos, assessorias universitárias e diversos outros meios, mas não é difícil encontrar os resultados desses números.

Um dado que possivelmente mostra os efeitos dessa disparidade foi publicado em 2009 por Ana Luiza Chieffi, então Secretária de Saúde do Estado de São Paulo, em pesquisa realizada em conjunto com a Santa Casa do estado. Nessa pesquisa, foram estudados 3.007 processos judiciais recebidos pela secretaria pedindo medicamentos e tratamentos de saúde, 80 foram descartados por não ter nome do advogado. Do restante, 74\% haviam sido patrocinados por advogados privados e $26 \%$ por advogados públicos (CHIEFFI, BARATA, 2009). Dada a probabilidade de pessoas de menor renda terem mais necessidade desse tipo de auxílio, e de a defensoria ter por público-alvo quase metade da população do país, é possível inferir que o número de pessoas sem atendimento é muito significativo. Não são excluídas questões culturais e sociais nessa questão, mas o acesso à Justiça é sistematicamente prejudicado pela falta de quadros para esse setor da população. 


\subsection{Duração dos processos}

Um segundo dado importante é o tempo de duração dos processos no Brasil. O índice apresentado no Justiça em Números é o seguinte:

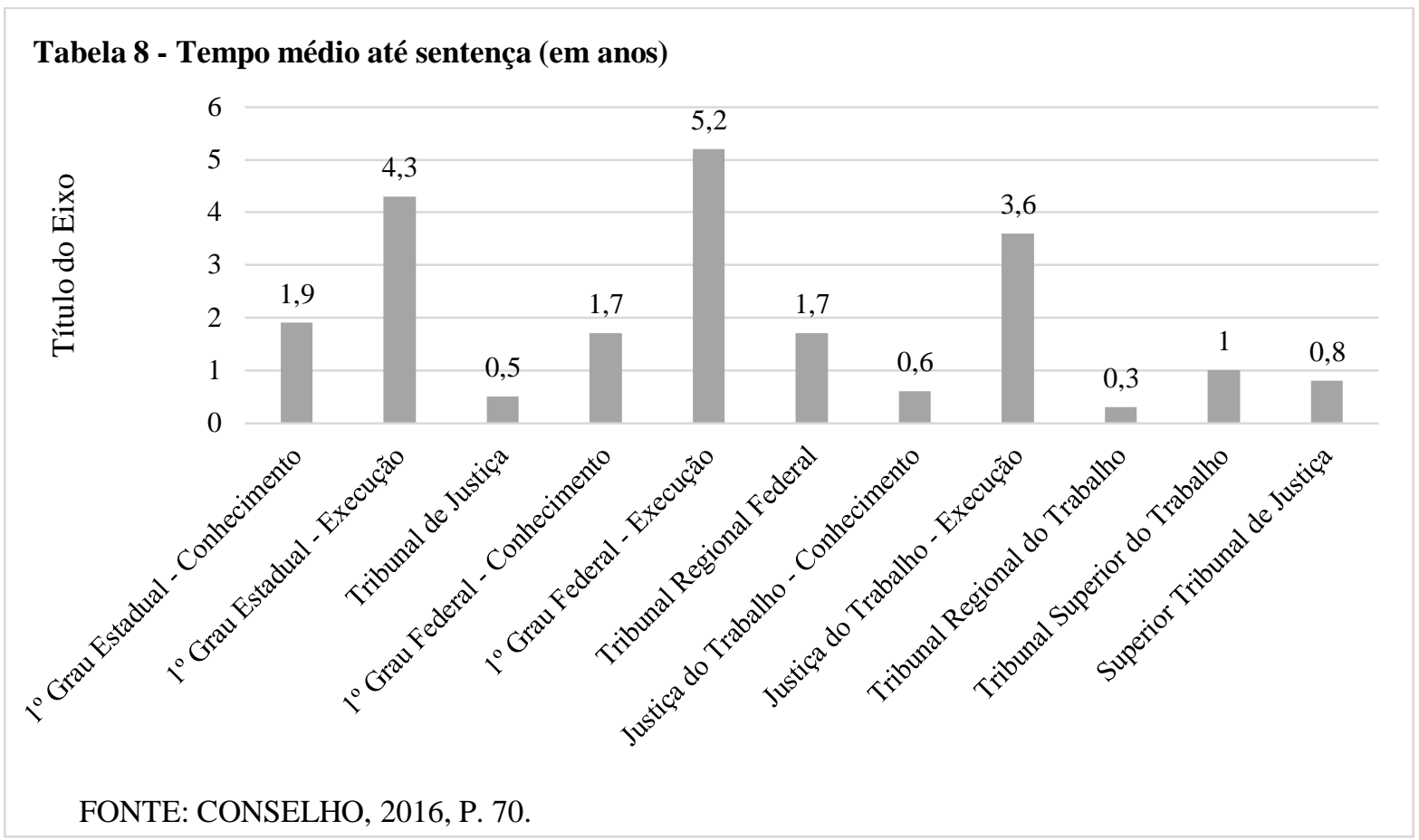

Esses tempos são apresentados permitindo a soma de acordo com a movimentação entre instâncias ${ }^{5}$. Assim, um processo de conhecimento que tenha tramitado no primeiro grau da Justiça Estadual leva, em média 1,9 anos (ou 1 ano e 11 meses) para sua solução final. Se ele ele tiver execução e ascender até o Superior Tribunal de Justiça, ele levará em média 7,5 anos (ou sete anos e seis meses). Os processos brasileiros, portanto, sem sair da média, podem tramitar por quase dez anos até ter julgamento nas instâncias superiores - e os que saírem, podem tramitar um tempo muito maior. Não raras vezes, a mora frustra o objetivo da tutela e, desafortunadamente, algumas vezes supera também a vida das partes.

Os dados, no entanto, não mostram realidades específicas e que, ainda que dentro dessas estatísticas, fazem com que esse tempo de tramitação se transforme em violações aos

\footnotetext{
${ }^{5}$ Os dados do CNJ não trazem estimativa sobre a demora caso o julgamento final seja feito pelo Supremo Tribunal Federal.
} 
direitos dos cidadãos. Assim, uma perspectiva específica sobre a tramitação de processos penais é acrescentada para enriquecer a reflexão.

Um estudo feito também pelo CNJ trouxe dados sobre o exercício da jurisdição penal no Brasil e a medida restritiva de liberdade mais grave, a prisão. Ele ajuda a ver as deficiências criando situações pessoais de profunda gravidade.

A pesquisa, realizada em janeiro de 2017, trata do percentual de presos provisórios no Brasil. Em alguns estados, esse índice chega a mais de $80 \%$ e, nacionalmente, ele é de $34 \%$. São 221.054 presos provisórios e 433.318 presos condenados no Brasil, segundo os dados fornecidos pelos presidentes dos tribunais de justiça de cada estado (CONSELHO, 2017, p. 34). O tempo médio da prisão varia entre 172 e 974 dias nos estados, estando a maior parte deles com média entre 200 e 400 dias (CONSELHO, 2017, p. 8). Em outras palavras, está dentro da média ficar preso por um ano esperando julgamento no Brasil, e há locais em que o normal é quase três.

Os dados presentes não permitem concluir os motivos desses índices, não há informação sobre o andamento processual. Por outro lado, o próprio CNJ aponta como problemas básicos do Poder Judiciário a litigiosidade, a morosidade e a falta de acesso à Justiça (CONSELHO, 2016, p. 31, 213 e 381-384) e provavelmente todos esses elementos estão presentes na formação desses números tão altos. A pesquisa mostra como deficiências atingem um número grande de pessoas e de forma profundamente invasiva. Os dados apresentados na primeira parte, de que 1.931 .542 novos processos criminais de conhecimento foram iniciados (CONSELHO, 2016, p. 72) mostram também que os números encontrados pelo CNJ não são apenas altos em valores absolutos, mas também que o problema envolve uma grande parcela dos processos.

\section{Conclusão}

Os dados apresentados permitem diversas conclusões, algumas distantes dos lugarescomum. A primeira é que, dada a alta taxa de litigiosidade na sociedade (ver Tabela 4), o número de advogados está em uma média internacional, sem destaque por ser alto ou baixo e há, por exemplo, três vezes menos advogados por processo do que no Japão (ver Tabela 6). Isso não significa que a formação dos advogados seja adequada, nem que profissionais tenham facilidade em se colocar no mercado. Essas questões, no entanto, precisam ser 
revisadas em seus contextos e dificilmente foram criadas pelo número atual de advogados ou seriam solucionadas pela simples diminuição.

A segunda conclusão é que há um alto número de processos por magistrado (ver Tabela 5). O aumento de produtividade pelas novas tecnologias, como o processo eletrônico, informatização, e o auxílio de servidores, permite que cada magistrado julgue um grande número de casos, mas os dados sobre a mora processual indicam que os esforços não tem sido suficientes. A quantidade de processos esperando por julgamento aumenta a cada ano no Brasil (ver Tabela 3) e as médias para julgamento podem chegar a uma década (ver Tabela 8). Os resultados disso estão, por exemplo, nos dados sobre prisões, que indicam um problema com impactos graves sobre a vida dos envolvidos, não representam mera uma espera alongada pela resolução das lides, mas uma questão civilizacional.

A terceira e última grande conclusão é que as defensorias públicas não terminaram o seu processo de implantação e continuam tendo um longo caminho a seguir. A quantidade de defensores em relação ao seu público-alvo é tão desigual, e tão distante do número de advogados privados, que mesmo sem dados concretos se pode concluir que uma parcela grande da população brasileira não tem acesso adequado à Justiça (ver tabela 7). As estatísticas concordam com o senso comum. Dados trazidos pela Secretaria de Saúde de São Paulo e os dados sobre prisões reforçam essa percepção, ainda que sejam excessivamente particulares para servirem como demonstração definitiva.

Essas conclusões indicam que resolver as dificuldades da Justiça no Brasil depende de ainda mais planejamento. Ele é feito com profundidade hoje, a existência de pesquisas tão completas é demonstração disso, mas os problemas antigos não foram superados. Um dado positivo é que há grande interesse da população nesse ramo profissional e uma estrutura pronta para a formação de juristas. Eles precisam, no entanto, ser qualificados adequadamente e o Estado, seja pelo incentivo à iniciativa privada e novos instrumentos de solução de conflitos, seja pelo aumento de sua burocracia, deve direcionar os profissionais para atuar onde estão os gargalos. Não há nenhum parâmetro que apresente uma barreira intransponível para o Brasil e ainda que as adaptações necessárias levem anos para serem implantadas, elas são viáveis.

\section{Referências}


AMERICAN Bar Association. ABA-Approved Law Schools. In Alphabetical Order. Disponível em: <https://www.americanbar.org/groups/legal_education/resources/aba_approved_law_schools/ in_alphabetical_order.html>. Acesso em: 19 mai. 2017.

Constituição da República dos Estados Unidos do Brasil. Disponível em: <http://www.planalto.gov.br/ccivil_03/constituicao/constituicao34.htm>. Acesso em: 20 mai. 2017.

Constituição da República Federativa do Brasil de 1988. Disponível em: <http://www.planalto.gov.br/ccivil_03/constituicao/constituicao.htm>. Acesso em: 20 mai. 2017.

L Lei $n^{o}$ 1.060, de 5 de fevereiro de 1950. Disponível em: <http://www.planalto.gov.br/ccivil_03/leis/L1060.htm>. Acesso em: 20 mai. 2017.

Lei $n^{o}$ 3.434, de 20 de julho de 1958. Disponível em: <http://www.planalto.gov.br/ccivil_03/leis/1950-1969/L3434.htm>. Acesso em: 20 mai. 2017.

. Ministério da Educação. Curso de Direito em Instituições de Educação Superior e Cursos Cadastrados. Disponível em: <http://emec.mec.gov.br/>. Acesso em: 19 mai. 2017.

CHIEFFI, Ana Luiza; BARATA, Rita Barradas. Judicialização da política pública de assistência farmacêutica e equidade. Cadernos de Saúde Pública, São Paulo, vol.25, n.8, p. 1839-1849, ago. 2009.

CONJUR. Total de advogados no Brasil chega a 1 milhão, segundo a OAB. Revista Consultor Jurídico, 18 de novembro de 2016. Disponível em: <http://www.conjur.com.br/2016-nov-18/total-advogados-brasil-chega-milhao-segundo-oab>. Acesso em: 19 mai. 2017.

CONSELHO Nacional de Justiça. Justiça em números 2016: ano-base 2015. Brasília: CNJ, 2016.

- Reunião Especial de Jurisdição. Brasília: CNJ, 2017. Disponível em: <http://www.cnj.jus.br/files/conteudo/arquivo/2017/02/b5718a7e7d6f2edee274f93861747304 .pdf>. Acesso em: 20 mai. 2017. 
DUQUE, Hélio. A inflação dos cursos de direito. Disponível em: <http://www.alvarodias.com.br/wp-content/uploads/2016/07/A-infla\%C3\%A7\%C3\%A3odos-cursos-de-direito-2.pdf >. Acesso em: 19 mai. 2017.

FERNANDES-FERREIRA, Hugo. Um exército de Doutores desempregados. Tribuna do Ceará, 17 de fevereiro de 2016. Disponível em: $<$ http://tribunadoceara.uol.com.br/blogs/tribuna-cientifica/ciencia-e-politica/um-exercito-dedoutores-desempregados/>. Acesso em: 20 mai. 2017.

GONÇALVES, Gabriella Vieira Oliveira; BRITO, Lany Cristina Silva; FILGUERA, Yasmin von Glehn Santos (orgs.). IV Dianóstico da Defensoria Pública no Brasil. Brasília: Ministério da Justiça, 2015.

LISBOA, Ana Paula. Não aprovados na OAB podem ganhar chance de atuação como paralegais. Correio Braziliense, de 6 de agosto de 2014. Disponível em: $<$ http://www.correiobraziliense.com.br/app/noticia/euestudante/ensino_ensinosuperior/2014/08/06/ensino_ensinosuperior_interna,441085/naoaprovados-na-oab-podem-ganhar-chance-de-atuacao-como-paralegais.shtml $>$. Acesso em: 19 mai. 2017.

MOSSINI, Daniela Emmerich de Souza. Ensino Jurídico: história, currículo e interdisciplinariedade. Tese apresentada à Banca Examinadora como exigência parcial para obtenção do título de Doutor em Educação: Currículo pela Pontifícia Universidade Católica de São Paulo. São Paulo: 2010.

MOURA, Tatiana Whately. Mapa da Defensoria Pública no Brasil. Brasília: ANADEP; IPEA; 2013.

NEGREIROS, Marcela Costa Fernandes; RODRIGUES, Rodolph Penna Lima. A assistência jurídica expansiva e as facetas da vulnerabilidade. In: BURGER, Adriana Fagundes; KETTERMANN, Patrícia; LIMA, Sérgio Sales Pereira (orgs.). Defensoria Pública: o reconheciento constitucional de uma metagarantia. Brasília; ENADEP, 2015.

NOVAES, Eugenio. OAB entrega a 142 faculdades selo de qualidade em ensino de direito. Notícia do Conselho federal da OAB, de 13 de janeiro de 2016. Disponívem em: <http://www.oab.org.br/noticia/29187/oab-entrega-a-142-faculdades-selo-de-qualidade-emensino-de-direito>. Acesso em: 19 mai. 2017. 
RAMSAYER, J. Mark Ramseyer; RAMSUSEN, Eric B. Rasmusen. Comparative Litigation Rates. Discussion Paper no. 681, 11/2010. Disponível em: <http://www.law.harvard.edu/programs/olin_center/papers/pdf/Ramseyer_681.pdf $>$. Acesso em: 19 mai. 2017.

SARAIVA, Alessandra; MARTINS, Diogo. IBGE: funcionários públicos eram 1,6\% da população brasileira em 2012. Valor Econômico, de 15 de março de 2013. Disponível em: $<$ http://www.valor.com.br/brasil/3046800/ibge-funcionarios-publicos-eram-16-da-populacaobrasileira-em-2012>. Acesso em: 19 mai. 2017.

SILVA, Antônio Álvares da Silva. Advogados em excesso. Disponível em: <https://www.trt3.jus.br/download/artigos/pdf/36_advogados_excesso.pdf $>$. Acesso em: 19 mai. 2017.

SILVA, José Fontenelle Teixeira da. Defensoria Pública no Brasil - Minuta Histórica. Disponível em: <http://www.jfontenelle.net/publicados4.htm>. Acesso em: 19 mai. 2017.

SILVA, Vânia Regina de Vasconcelos Reis e. Os processos de ensino e de aprendizagem no curso de Direito. Dissertação apresentada à Faculdade de Filosofia, Ciências e Letras de Ribeirão Preto da Universidade de São Paulo como requisito para obtenção do título de Mestre em Psicologia. Ribeirão Preto: 2012.

STRECK, Lenio Luiz. Curso de tecnólogo jurídico: assumimos a rabulice de vez no ensino de Direito. Consultor Jurídico, 1 de agosto de 2016. Disponível em: <http://www.conjur.com.br/2016-ago-01/streck-curso-tecnologo-juridico-rabulice-ensinodireito>. Acesso em: 19 mai. 2017. 